\title{
Conservative Liberalism as a Conceptual Basis of Modern Humanitarian Policy*
}

\author{
Marina Ivleva \\ Faculty of Humanities and Social Sciences \\ Department of Social Philosophy \\ Peoples' Friendship University of Russia \\ 6 Miklukho-Maklaya Street \\ Moscow, Russian Federation 117198 \\ E-mail: ivleva_ml@pfur.ru
}

\author{
Sergey Kurilov \\ National Research University \\ Moscow Power Engineering Institute \\ Moscow, Krasnokazarmennaya, d.14, 111250 \\ E-mail: kurilov85@mail.ru
}

\begin{abstract}
The article examines the philosophical foundations of the socio-political concept of conservative liberalism. The thesis of the relativity of political ideologies and their dependence on socio-historical conditions is upheld. It is shown that liberal and conservative measures are in practice inverted. Values in the field of humanitarian policy are analyzed. The idea of the primacy of mental improvement of society in relation to the progress of external social forms is substantiated. The article elaborates the basic principles of the conservative liberal conception as a strategy of modern humanitarian policy.
\end{abstract}

Keywords - conservative liberalism; conservatism; liberalism; humanitarian policy; personality; state; society; monodualism; monopluralism; political ideologies

\section{INTRODUCTION}

The key idea of conservative liberalism about the synthesis of freedom and order is of practical importance in the sphere of contemporary humanitarian policy. The aim of the humanitarian policy is to harmonize relations between people, to create optimal conditions for the hostel. The humanitarian policy functions as a set of decisions, with the help of which conditions for the cultural development of the society, the realization of intellectual requests and creative abilities of people are formed.

The humanitarian sphere which understands like the sphere of relations between man and the state, man and society - is closely connected with the problem of the ontological status of the two principles of social existence: the personality and the power. In this sphere, a serious question arises- the relationship between the rights and duties of the individual and the state in the context of relations with each other, on the delineation of "spheres of influence" and mutual respect. The state in its interests is always oriented towards a certain bureaucratic control and regulation of the sphere of relations with citizens. However, the development of culture is possible only in conditions of progressive liberation of the individual, which is guaranteed by the Constitution. The rights to creativity, the choice of values,

*The publication has been prepared with the support of the RUDN University Program 5-100. rest, the use of cultural goods, education, the association with other people in the particular unions, communities and interest groups mean the gradual expansion of the social opportunities of the personality.

This rather controversial situation develops two lines of social activity which are difficult to correlate with each other. In the conservative and liberal ideology, two principles are opposed: the individual and the state. In any era in society there is the problem of harmonization of traditions and innovations, the correlation of creative tendencies and ordering. This dilemma can be formulated as an age-old socio-ontological question: to preserve or transform. One of the theorists of the conservative liberal concept, S.L. Frank, wrote that it is necessary to establish a balance between "ancient cultural and historical life feelings and skills" and creative initiative and the living power of spiritual creativity "[1].

The ideological contradictions between the new and the old, the traditional way of life and cultural modernization give rise to disagreements that do not come to a consensus. This misunderstanding is often due to the fact that philosophical and political discussions are not based on facts, but on the values of adherents of a certain ideology. Effective social communication is possible only in conditions of free creative and intellectual dialogue. These conditions can only be created "from above" - the state, but the duty of citizens is to develop and maintain an atmosphere of dialogue.

\section{VALUE BASES OF POLITICAL IDEOLOGIES AND REFUSE OF THEIR ABSOLUTISATION}

Trying to apply humanitarian technologies, we can find out contradictory trends. Today in the system of the world political space we observe basically two types of countries: where the state dominates, and where liberal values prevail in domestic and foreign policy. The political experience of different countries shows the inconsistency of the ideas of liberalism and conservatism in their radical options. The opportunities and "resources" of conservative and liberal ideology are visible only if they are compared. Their advantages are evident with an integrated approach, within 
which a new ideology is developed that takes into account the specifics of each and removes contradictions. Despite the fact that today in the political space there are such trends as neoliberalism, neoconservatism, they require a revision of strategies for their implementation in practice. Political ideas cannot be considered in isolation from the historical period, social, economic, political and cultural conditions.

It should be noted that countries with a social democratic development vector (for example, the Scandinavian countries), in our opinion, are approaching a conservativeliberal ideal. In practice, we observe that the most economically and culturally developed countries tend to follow this path, combining freedom with a thoughtful organization of state planning.

The life of people in society is a rather complicated and confusing tangle of contradictory phenomena. Forms of social life exist as an interaction of interests, constantly in conflicts of different levels. In the deep basis of these conflicts, in our opinion, the interests of social preservation, on the one hand, and social liberation, on the other hand, lie. This is explained, first of all, by socio-psychological reasons. It is known that young people always act as a catalyst for progress, older people who have acquired a certain experience are prone to preserve their accumulated wealth, it is more difficult for them to go beyond the framework of the established system of relations.

While referring directly to policy issues, the social theorist should not absolutize its significance - this is the first message that must be accepted for a qualitative analysis of the humanitarian sphere. If we draw parallels with medicine, politics is rather a conservative treatment, rather than an "operating" surgery. In emergency situations, when people's survival issues or a way out of a deep economic crisis, a social impasse, then operative intervention is, of course, possible within a reasonable framework. However, man and his life is the first axiom both in cultural-historical and in genetic terms [2]. "The main functional purpose of politics is to educate society, to create conditions for the development of man's spiritual, moral and physical powers, and not total control. The limit of politics should be the regulation of relations in society, tk. it cannot fully cure society, not to mention its spiritual and moral improvement, by its own means "[3].

Conservative liberal theory proceeds from the message that the person is the "alpha" of social being, and "omega" is the state. Personality is the point of the report; the state is the point of completion and meaning of social reality. In the concept of monodualism, developed by S.L. Frank, the idea is based that the personality and the state are two principles in unity, in a bunch; they cannot be dismembered [4]. Conflicts of interests of these two sides can be reconciled, if we take the above-mentioned idea as the basis of social development. An adequate version of social development and the device of S.L. Frank saw a combination of conservative and liberal principles, the synthesis of which rejects the extremes of conservative-conservative theory in the spirit of late Enlightenment and liberal theory in its Anglo-American version.
In the era of modern times - the period of the emergence of materialism, atheism, utilitarian and pragmatic values, there is a gap between social construction and ethics in its classical version, ethics that proclaims absolute values. Within the framework of the socialist model in the 20th century, the prevailing values of justice and solidarity did not have an absolute ethical basis. Socialism meant first the construction of a materially prosperous society - a society of prosperity. The socialism of the Soviet, Chinese, Eastern European model, proclaiming the building of communism, placed the state above man, justifying it with the idea that at the initial stage society cannot cope with the tasks of social creation.

Putting a person above the state, political theory, and then practice comes to an anarchic model. In the case of recognition of the primacy of the state over the personality, an authoritarian model is formed, which in the course of time assumes the features of a totalitarian system. The society is formed both "from above", and "from below", this process assumes both mechanics, and organic. Social mechanics is the source of the state, which in its essence - the beginning of organizing and organic - this is the sphere of interaction between people and all forms of their spiritual creativity.

The concept of conservative liberalism emphasizes that the state's regulation of the sphere of relations with people and between people is more of an appendix than an end in itself. In this thesis, we can see a certain depreciation of the role of the state as a social institution. However, this idea has an ethical-anthropological basis. Man, in his limited capacity can never resist the machine of power and the social system, therefore the value of individual freedom is the starting point of social and cultural creation. The state has external and internal functions of its purpose: organizational and systematic and the function of creating conditions for a spiritual and moral climate.

If the personality can be regarded as an innovative, creative beginning, then the state is a conservative, traditional beginning. Personality is a kind of catalyst, and the state is a battery, both of these functions support progress in a full-fledged form. The functions erected in the absolute create a distorted form of social and state relations. The true, unalienable existence of both the individual, society, and state is possible only in conditions of a positive unity of these seemingly opposite categories.

In the framework of the conservative liberal approach, civil society is understood as a unity that develops not mechanically, but creatively, through the interlacing of human wills in the course of their life and activities. The state is not understood as a coercive organization that absorbs a person, but as the beginning that organizes freedom. With a pragmatic view, the ideas of the conservative liberal concept seem utopian. However, this accusation is usually presented to all social and philosophical concepts, within the framework of which speculative principles are formulated. The problem is that at the level of ordinary consciousness there is no connection between theoretical constructions and practical actions. If we turn to the sources of various social actions, then even a shallow 
reflection, we will see a linear relationship between ideological attitudes and concrete forms of social order.

In the socio-philosophical ideas of domestic liberal conservatives and conservative liberals KD. Kavelina, B.N. Chicherina, P.B. Struve, SL Frank developed ontological, methodological, axiological foundations of conservativeliberal doctrine [5] [6] [7]. However, it is necessary to identify those conceptual attitudes with which you can translate this doctrine into practice. These attitudes are formed on the basis of the doctrine of the "integrity" of being and cognition, developed in the Russian religious philosophy of the Silver Age by such thinkers as V.S. Soloviev, N.O. Lossky, S.L. Frank et al. [8] [9] [10]. According to V.S. Solovyov, being monoplurastic, the unity and plurality of everything existing is in a supra-rational synthesis. "Society is augmented, or expanded, personality, and personality compressed, or concentrated, society" [11]. Conservative and liberal tendencies of social life are an inseparable unity.

\section{INVERSION OF CONSERVATIVE AND LIBERAL IDEAS}

Conservative and liberal ideas in practice are implemented in an inverted form. Releasing citizens from the dictates of society, the state organizes social life. Conversely, by protecting the society, limiting the tendencies of destructive creativity, the state creates conditions for the release of hidden forces. For example, increasing the level of demography in a country that is traditionally referred to as conservative policy methods, with more convex optics, is a liberal measure. By increasing the number of citizens in the state, conditions are created for the emergence of individuals who think outside the box and move the history of their country. Suffice it to recall the demographic rise in the Russian Empire in the XIX century, when many outstanding people discovered the Golden Age of Russian culture. By refusing to dominate the economy, political institutions of power make it possible to create mechanisms for effective regulation of the market. These measures at the level of traditional ideological thinking refer to liberal measures, but in the future, they generate conservative tendencies that preserve economic institutions in society. The optimality of strategies for social development will be checked by the fact that in its framework dialectically synthesize opposing, alternative attitudes, ideas, methods, and technologies. The solution of the tasks of the state structure, the accuracy of effective forecasting depends on the level of complexity of the analytical approach in humanitarian policy.

The problem of reconciling opposing methods and technologies, harmonizing views, finding common ground in a dialogue is overcome in the idea of refusing to absolutize all ideologies. In this case, the question naturally arises of the cornerstone - the position that determines the social practice. Historical experience shows that without an idea in which specific theories and projects are focused, understanding of development is impossible. The solution of this question is possible when the social and state idea is based on an understanding of the primacy of ethical education and moral improvement in relation to the external, formal goals of the state. Functional and regulatory ordering of society must be preceded by time moral perfection, spiritual change for the better.

The program, developed in the Age of Enlightenment, in which scientific and technological progress was identified with socio-cultural progress in general, narrowed the understanding of development. The development of only external spheres, even such important spheres as science and technology, politics, law, economics, cannot be absolutized and divorced from humanitarian development in general. The genuine, not illusory, development of society is indexed by the transformation of the personality, its spiritual potential This is the last goal of cultural evolution. Expansion of material wealth is a means, and not the goal of a historical process, turned into the future.

In the work "Spiritual Foundations of Society", S.L. Frank offers an original and, for a superficial glance, the utopian idea of "politics of love," based on Christian values [12]. He believed that in social life the dualism of the spiritual and material, external and internal levels of being is visually visible. "The politics of love" is a set of views and attitudes in the sphere of relations between people and social institutions, the essence of which is reduced to thinking about the anthropocentric background of humanitarian policy.

The state as a subject of activity has two incarnations of its purpose: the external - the protection of society from evil and the internal - overcoming the moral imperfections of people and social institutions. The relationship between people in the state is a direct consequence of humanitarian policy. Evil, alienation, hostility is largely due to the education of a person in the family, school, higher education. Institutes of humanitarian policy are the vehicles of not only specific political technologies, but also create a certain atmosphere in which the future citizen is formed. The humanitarian task of the state is not the external regulation of forms of social relations, but the creation of comfortable conditions for the spiritual development of citizens and the establishment of a dialogue between people and social institutions.

In the era of "developed" democracy, it is believed that the main regulator of the humanitarian sphere is the path of its automatic transformation through legal and socio-political mechanisms. However, a profound change in social life is possible at the level of consciousness in the first place, and only in the second place - at the level of practice. This path is thorny, but it is possible, if we use theological terminology, at the level of "repentance," that is, mental change of thoughts and life. Building democracy cannot be oriented only to social and political innovation; otherwise it will not in practice look like a true democracy. Promotion of democratic values in humanitarian policy implies the preservation of social and cultural traditions that create a spiritual atmosphere - the environment in which relations between people are formed.

In conservative-liberal synthesis, the birth of a not illusory democracy is possible, because in this doctrine, the interests of members of society are reduced to the idea of the self-worth of each individual, without gender, national, economic, political, legal and cultural restrictions. "The 
person is sacred in itself," noted S. Frank, "because she ... is the bearer and creator of spiritual values, the realization of which in the socio-historical life forms the content of culture and is the highest and last task of political construction" [13]. Social development always represents the dialectic of personal growth and the level of the socio-cultural development of the state: the social structure depends on the individual's self-identity; the mind and behavior of the individual are directly dependent on the organization and efficiency of public and political institutions.

\section{CONCLUSION}

The basic principles of the conservative-liberal project of a socio-political system can be formulated as follows.

- The humanitarian policy must proceed from the idea of creating conditions not so much for external modernization as for internal modernization. In practice, this looks like a policy of reasonable tolerance, not reaching the point of absurdity of tolerance for the emergence and development of various forms of social creativity.

- Specific strategies of policy in the humanitarian sphere are formed on the basis of the thesis that in any culture there is an idea-a shrine-that is, a set of established value orientations. The presence of such values does not mean the adoption of any specific ideology, but the orientation of society on ethical principles, formed by world religions and humanistic ethics.

- The values of conservatism and liberalism, implemented at the level of humanitarian policy, are introduced as reconciling, combining the opposite tendencies of social life. By creating conditions for the development of creative potential, the state creates, unites people with different views, respecting in this case their power.

The author's view is based on the idea that conservative liberalism is the most acceptable, from the point of view of the evolutionary path of development of society, ideology. The system of conservative-liberal attitudes corresponds to the social ideal and needs of a particular person as a citizen and a person. Based on universal human values, this system is the most viable and durable in the event of the rejection of all radical encroachments and the adoption at the level of social and state consciousness of the thesis of the equivalence of all ideologies.

\section{REFERENCES}

[1] S.L. Frank. Spiritual foundations of society // Collection: comp. PV Alekseev. - M.: Republic, 1992. - 510 p. - C. 244.

[2] M.L. Ivleva, E.M. Kurmeleva, S.V. Rudanovskaya. Man, and society in the context of modernity (review of the All-Russian scientific conference with international participation) // Questions of Philosophy. 2018. №4. C.191-195

[3] S.N. Kurilov. The concept of conservative liberalism in social philosophy Frank: monograph. -M.: BIBLE-GLOBE, 2016. - 156 p. C.114
[4] S.L. Frank. Spiritual foundations of society / / Collection: comp. PV Alekseev. - M.: Republic, 1992. - 510 p. -

[5] K.D. Kavelin. The peasant question // Collected works of K.D Kavelina: T. 1-4. - SPb: type. M.M. Stasyulevich, 1898.-T.2.-1258 p.

[6] B.N. Chicherin. General state law. - M.: Zertsalo, 2006. - 536 p.

[7] P.B. Struve. Great Russia. Book. 2. - M., 1911. P.153-154.

[8] V.S. Solovyov. Justification of the Good // Соловьёв В.C. Compositions. In 2 vols. M., 1988. T. 1. - 892 p.

[9] N.O. Lossky. History of Russian Philosophy / N.O. Lossky; Per.s English-M.: Soviet writer, 1991.- 480s.

[10] S.L. Franc. Subject of knowledge. The soul of man. - St. Petersburg Science, 1995.-655s.

[11] V.S. Solovyov. Justification of the Good // Соловьёв В.C. Compositions. In 2 vols. M., 1988. T. 1. - 892 p. - C.65

[12] S.L. Franc. Spiritual foundations of society // Collection: comp. PV Alekseev. - M.: Republic, 1992. - 510 p.

[13] S.L. Franc. Spiritual foundations of society // Collection: comp. PV Alekseev. - M.: Republic, 1992. - 510 p. 